\title{
ENTRE TÉCNICA E REFLEXÃO: UM ESTUDO DA FUNÇÃO SOCIAL DAS BIBLIOTECAS PÚBLICAS A PARTIR DA TEORIA CRÍTICA
}

\section{BETWEEN TECNIQUE AND REFLECTION: A STUDY OF THE ROLE OF PUBLIC LIBRARIES BASED ON CRITICAL THEORY}

\author{
Mariana Rodrigues Gomes de Melloa \\ Daniel Martínez- Ávila \\ Leda Maria Araujoc \\ Marta Lígia Pomim Valentim ${ }^{d}$
}

\begin{abstract}
RESUMO
Introdução: As bibliotecas públicas se constituem em espaços de emancipação, através das trocas, partilhas, práticas que conectam e transformam os cidadãos e, consequentemente, a sociedade na qual estão inseridos. Assim, questiona-se: o bibliotecário está preparado para promover ações que contribuam à formação de seres autônomos, críticos e almeja isso? Objetivo: Estabelecer a inter-relação entre o papel da biblioteca pública, a razão subjetiva (técnica) e a razão objetiva (emancipatória) mediante a Teoria Crítica, destacando-se os filósofos Adorno e Horkheimer. Metodologia: Aplicou-se o método "Análise do Conteúdo" mais especificamente a técnica "Análise Categorial", cujas categorias foram estabelecidas a posteriori. Resultados: A partir da aplicação de um questionário para dois coordenadores de bibliotecas públicas, evidenciou-se que além da dimensão técnica que a biblioteca pública traz, que é inerente ao seu funcionamento, há outras que requerem uma reflexão maior, pois o bibliotecário tem, também, a função de mediador da informação e educador no sentido lato, orientando o acesso, a busca de informação e fomentando a vontade de aprender dos usuários. Conclusões: O processo emancipatório, a partir do aporte da Teoria Crítica, perpassa pela reflexão, sensibilização e independência. Organizar os espaços das bibliotecas públicas de modo a instigar a vontade de aprender, facilitando o acesso e a busca de informação é um passo importante na promoção da autonomia.
\end{abstract}

a Doutoranda do Programa de Pós-Graduação em Ciência da Informação da Universidade Estadual Paulista (PPGCI-UNESP). E-mail: mariana.rg.mello@unesp.br

b Doutor pelo Programa de Doctorado en Documentación pela Universidad Carlos III de Madrid. Docente do Programa de Pós-Graduação em Ciência da Informação da Universidade Estadual Paulista (PPGCI-UNESP). E-mail: martinez.avila@unesp.br.

c Doutoranda do Programa de Pós-Graduação em Ciência da Informação da Universidade Estadual Paulista (PPGCI-UNESP). E-mail: le-araujo@hotmail.com.

d Doutora em Ciências da Comunicação pela Universidade de São Paulo (USP). Docente do Programa de Pós-Graduação em Ciência da Informação da Universidade Estadual Paulista (PPGCI-UNESP). E-mail: valentim@marilia.unesp.br. 
Descritores: Função Social das Bibliotecas Públicas. Biblioteca Pública. Teoria Crítica. Espaço Maker.

\section{INTRODUÇÃO}

A biblioteca pública apresenta desde suas origens uma importante função social que vai muito além do simples tratamento técnico das informações (TOTTERDELL, 1978). Não há dúvida sobre a importância da técnica, mas ela não deve sobrepor a reflexão, a crítica e o processo criativo que o bibliotecário necessita ter ante as necessidades e as demandas da população. Caso contrário, a profissão de bibliotecário se apresentaria como o reflexo de uma consciência coisificada, cuja atuação profissional seria facilmente realizada por sistemas automatizados e/ou robóticos. A sobreposição da técnica significaria um trabalho pela sobrevivência, sem colocar a ideia de finalismo - objetivo maior que vise o bem comum - nas ações do bibliotecário. Partimos da ideia de que o bibliotecário, destacando-se neste artigo aquele que atua em biblioteca pública, possa ir além do tratamento técnico da informação que é realizado sem reflexão crítica.

O problema de pesquisa incide em refletir a dimensão social da biblioteca pública, mediante o seguinte questionamento: o bibliotecário está preparado para promover ações que contribuam para a formação de seres autônomos, críticos e almeja isso? Posto isto, objetivamos analisar se as ações realizadas nas bibliotecas públicas podem auxiliar no processo de emancipação de seus usuários, principalmente de crianças e de adolescentes. Para tanto, faremos a inter-relação entre o papel da biblioteca pública, a razão subjetiva (técnica) e a razão objetiva (emancipatória) ante a Teoria Crítica, destacando-se os filósofos Adorno e Horkheimer. Após a discussão sobre os elementos fundamentais da Teoria Crítica e do papel do bibliotecário no processo emancipatório dos usuários, destacando a dimensão social das bibliotecas públicas, como makerspaces - apresentaremos os resultados oriundos da aplicação de um questionário para dois coordenadores de bibliotecas públicas de uma cidade de representatividade no interior do Paraná. 
A fim de analisarmos os resultados e responder ao objetivo principal desta pesquisa, ou seja, refletir se as ações realizadas nas bibliotecas públicas podem auxiliar no processo de emancipação de seus usuários, aplicamos o método "Análise de Conteúdo" de Bardin (2009) adaptando-o para a sistematização e análise das informações coletadas. Segundo Silva e Gobbi (2005), na compreensão que têm de Bardin, inexiste na Análise do Conteúdo um sistema rígido de utilização. Sendo assim, o pesquisador pode usar desta flexibilidade, sem deixar de imprimir nitidez ao referencial e à metodologia. A Análise do Conteúdo possui três fases: pré-análise, exploração do material, tratamento dos resultados: inferências e interpretação (BARDIN, 2009).

Na leitura que Silva e Valentim (2019) fazem dessas três fases:

\begin{abstract}
A pré-análise visa a sistematizar as ideias iniciais, sendo a base para o desenvolvimento das fases seguintes. Geralmente inclui a escolha dos documentos a serem submetidos à análise, a formulação das hipóteses e dos objetivos, bem como a elaboração de indicadores que fundamentem a interpretação final (BARDIN, 2009, p. 121). A fase de exploração compreende a codificação do material que compõe o corpus de análise, feita a partir de critérios previamente estabelecidos. O tratamento dos resultados condensa e evidencia as informações fornecidas pela análise, e pode resultar em quadros, diagramas, figuras e modelos. Diante disso, o pesquisador propõe inferências e interpretações a propósito dos objetivos previamente determinados.
\end{abstract}

A Análise do Conteúdo, portanto, consiste em um método versátil, capaz de ser aplicado em diversos contextos, sendo adequado às pesquisas qualitativas, se utilizando de diferentes técnicas, conforme os objetivos, tais como: Análise Categorial; Análise de Avaliação; Análise de Enunciação; Análise Proposicional do Discurso e Análise de Expressão (SILVA; VALENTIM, 2019). $\mathrm{Na}$ nossa pesquisa, conforme demonstramos nos resultados, adaptamos a técnica Análise Categorial, que "[...] funciona por operações de desmembramento do texto em unidades, em categorias segundo reagrupamento analógicos" (BARDIN, 2009 apud SILVA; VALENTIM, 2019, p. 330).

A pesquisa é de natureza exploratória, na medida em que poucos estudos têm analisado o processo de emancipação no âmbito da biblioteca pública, aliando a Teoria Crítica à Ciência da Informação neste contexto. Tal fato 
demonstra a necessidade de pesquisas nesta área, almejando determinar indicadores, políticas e práticas para sua aplicação nas bibliotecas públicas. A representatividade da amostra reduzida se justifica pelo caráter exploratório e pelo fato de tratar-se de aspectos teóricos, cuja validade está sendo testada em bibliotecas seletas. Portanto, o presente trabalho apresenta questões iniciais a serem debatidas e abre portas à outras discussões que poderão ser vislumbradas futuramente tornando-se ações afirmativas ou auxiliando na elaboração de políticas públicas que viabilize melhor a questão.

\section{TEORIA CRÍTICA E O PAPEL DO BIBLIOTECÁRIO NO PROCESSO EMANCIPATÓRIO DOS USUÁRIOS}

O contexto indicado na seção introdutória desta pesquisa nos remete à outra questão filosófica: no contexto da Pós-Modernidade nossas atitudes são refletidas, livres, críticas e conscientes, ou perdemos a faculdade de pensar? No intuito de refletir sobre esta questão e ao final poder estabelecer um paralelo sobre o papel das bibliotecas públicas no processo de emancipação, convém expormos um pouco da Teoria Crítica da Escola de Frankfurt, destacando-se as reflexões de Adorno e Horkheimer da primeira geração.

A Teoria Crítica foi idealizada a partir de 1924 no Instituto de Pesquisas Sociais da Universidade de Frankfurt na Alemanha (CONTRIN; FERNANDES, 2013). Ela se contrapõe à teoria tradicional de origem cartesiana, reducionista, fragmentada, técnica, acrítica, que se limita a explicar o fenômeno tal como se apresenta, mediante o olhar distante do observador, que se reduz a observar o objeto, sem emitir um parecer crítico. Para expormos aspectos da Teoria Crítica que tenham relação direta com nossa temática, utilizaremos três obras: "Eclipse da Razão" (HORKHEIMER, 2013), "Dialética do Esclarecimento" (ADORNO; HORKHEIMER, 1985) e "Educação e Emancipação" (ADORNO, 2011), especialmente o capítulo "Educação após Auschwitz".

Horkheimer e Adorno defendem que a verdadeira racionalidade se expressa por meio da reflexão e da autonomia e não pelo domínio técnico. O conhecimento genuíno advém da racionalidade crítica e não da apreensão da 
Ciência enquanto técnica. Não é a mera reprodução de conceitos de modo heterônomo e acrítico. Nessa perspectiva, classificam duas espécies de razão: a subjetiva, também denominada de razão instrumental e a objetiva, tida como emancipatória. A primeira está inter-relacionada a ideia da técnica da sociedade capitalista, sem um fim axiológico e autoconsciente. "A técnica é a essência desse saber, que não visa conceitos e imagens, nem o prazer do discernimento, mas o método, a utilização do trabalho de outros, o capital" (ADORNO; HORKHEIMER, 1985, p. 18).

Por outro lado, a razão objetiva está vinculada a um fim, uma reflexão, um valor e não apenas a uma vantagem lucrativa. A razão objetiva era empregada pelos filósofos gregos na Antiguidade, como Sócrates, Platão e Aristóteles. Segundo Horkheimer (2013), Sócrates morreu lutando contra a razão subjetiva, defendida pelos sofistas, ou seja, um conservadorismo ideológico, relativista, travestido de progresso, mas que verdadeiramente estava à mercê dos interesses pessoais. Aristóteles, apesar de ser um filósofo que tinha um viés científico, um dos primeiros empiristas, preservou o que chamava de causa final em seus ensinamentos e ações. Nesse sentido, afirma que "[...] se há alguma coisa que seja o fim de nossos atos, essa coisa será o bem realizável, e se houver várias coisas, serão elas" (ARISTÓTELES, 1973, p. 251).

Na concepção de Horkheimer (2013) esses filósofos almejavam construir um sistema hierárquico de todos os seres, incluindo o ser humano e seus fins. $O$ grau de racionalidade de uma pessoa era determinado de acordo com sua harmonização com o conjunto, e não somente com seus objetivos individuais. $O$ grande desafio dessas escolas filosóficas, portanto, foi o de combinar os interesses particulares, como o de autopreservação, com a ideia de finalismo que engloba o bem geral.

A razão objetiva seguiu seu curso com filósofos medievais, especialmente com Tomás de Aquino que uniu fé e razão, inspirando-se em Aristóteles. No entanto, a razão objetiva começa a perder força ante o mecanicismo cartesiano, relacionado com a metáfora do relógio, cujas engrenagens e movimentos precisos e incessantes, adentram a esfera do trabalho, das relações sociais e 
das relações pessoais, transformando as pessoas em máquinas, coisificando suas consciências. Sob esta ótica:

"[...] o preço da dominação não é meramente a alienação dos homens com relação aos objetos dominados; com a coisificação do espírito, as próprias relações dos homens foram enfeitiçadas inclusive as relações de cada indivíduo consigo mesmo" (HORKHEIMER, 2013, p. 35).

Sob esse ponto de vista, a ideia mecanicista toma uma proporção muito maior do que a idealizada pelo próprio Descartes, a partir da Revolução Industrial. Dissocia, assim, a ideia de fim como bem comum; o lucro e os interesses particulares se tornam fins em si mesmos. "É como se o próprio pensamento tivesse reduzido ao nível do processo industrial, submetido ao programa estrito, em suma, tivesse se tornado uma parte e uma parcela da produção" (HORKHEIMER, 2013, p. 31).

Desse modo, a ideia de progresso a qualquer custo que permeava 0 discurso científico-tecnológico, entre a metade do Século XIX e início do Século XX, reduz a razão totalmente ao domínio instrumental do mundo e ela não se dissocia apenas da religião, mas também da ética. É neste contexto que reside o problema. Na visão de Horkheimer acerca do tema:

A ideia de que um objeto possa ser racional por si mesmo -
fundamentada nas qualidades que se podem discernir dentro
dele - sem referência a qualquer espécie de lucro ou vantagem
para o sujeito, é inteiramente contrária à razão subjetiva, mesmo
quando esta se ergue acima da consideração de valores
utilitários imediatos e se dedica a reflexões sobre a ordem social
como um todo (HORKHEIMER, 2013, p. 14).

Sob esta análise, a ausência de autonomia e reflexão torna a razão instrumental reducionista, subjetiva, ratificada pelo positivismo e pragmatismo e, portanto, heterônoma. A hetoronomia, na visão de Adorno (2011), implica na dependência de normas e mandamentos externos, que não são assumidos pela razão própria das pessoas. Se assim procede, os indivíduos aceitam o que thes é imposto por uma oligarquia, mesmo que exerçam alguma resistência, concebem isto como algo lógico e necessário. A sociedade molda os indivíduos à mercê de seus anseios, a fim de que absolvam e aceitem tudo sem questionar.

Adorno (2011) também afirma que a fetichização da técnica implica na 
incapacidade de amar, ressaltando que não fala de modo sentimental ou moralizante, mas como expressão da carente relação com os outros, com aqueles que se deixam dominar pela tecnocracia. São pessoas "[...] inteiramente frias e precisam negar também em seu íntimo a possibilidade do amor, recusando de antemão nas outras pessoas o seu amor antes mesmo que se instale" (ADORNO, 2011, p. 133). O mesmo autor complementa: "[...] a capacidade de amar, que de alguma maneira sobrevive, elas precisam aplicálas aos meios" (ADORNO, 2011, p. 134). Na acepção de Adorno (2011), sob a mesma lógica, também surgem os preconceitos relacionados ao autoritarismo de um sujeito experimental, repertório da consciência coisificada.

Adorno (2011) exemplifica a questão da ausência da ideia de finalismo e da fetichização da técnica, constatando que quando os meios sobrepõem os fins, é possível construir uma estrada de ferro que leve pessoas à Auschwitz, sem pensar no que possa ocorrer com elas, ou seja, nos fins. Basta que os meios sejam eficazes para fazer o que foi determinado, isto é, a construção de um sistema ferroviário eficaz. Para Adorno, se os indivíduos não fossem tão indiferentes aos que não constituem seu núcleo familiar ou de amizades, pelos quais mantém um interesse concreto, Auschwitz nunca teria sido possível, simplesmente porque as pessoas não teriam aceito.

Adorno (2011) defende que a exigência de emancipação é evidente em uma democracia. Resgatando o livro de Kant "O que é esclarecimento" podemos compreender que a "[...] emancipação é a libertação, é tornar-se autônomo, é construir-se na luta por parte do sujeito, é a consciência de uma complexa dialética entre alienação e "redenção" (KANT, 1985, p. 100). O que no entendimento kantiano "[...] inerva também a pedagogia, a qual teoricamente se reconhece como guiada, sempre por um desejo de emancipação (do sujeito, da sociedade) [...]" (KANT, 1985, p. 100). Todavia, para Adorno (2011), toda tentativa de aduzir a sociedade à emancipação, sempre estará submetida à enormes resistências, justamente porque tudo o que é nocivo no mundo, sempre encontra defensores contumazes que buscarão demonstrar que o conceito de emancipação está totalmente superado ou, ainda, só pode ser concebido no 
plano idealista como algo utópico, que nunca poderá ser visto na prática. Para Demo (2000, p. 39):

Emancipar-se, com efeito, implica capacidade de confronto, quebra da ordem vigente considerada impositiva e injusta, consideração de alternativas. Sua face disruptiva parece evidente, porque conhecer implica intrinsecamente questionar $[\ldots]$.

Nessa lógica, a única alternativa vislumbrada por Adorno (2011) para chegarmos à emancipação ocorre por meio de ações no campo da Educação1, por intermédio das poucas pessoas interessadas em investir esforços nessa direção, seja em educar para a resistência ou para a contradição. O princípio da autonomia é, portanto, a única maneira de chegarmos à emancipação, expressa no modo como cada pessoa busca a possibilidade de direcionar suas ações, de acordo com uma lei ética; um processo individual, mas com caráter dialógico, que exige respeito à dignidade de todos os envolvidos. Nesse sentido, destaca Paulo Freire que o "[..] respeito à autonomia e à dignidade de cada um é um imperativo ético e não um favor que podemos ou não conceder uns aos outros" (FREIRE, 2011, p. 58).

Nesse aspecto, podemos nos remeter ao papel da biblioteca pública como fonte de promoção e respeito à autonomia, a partir da sua concepção como algo desejável e realizável, por meio de ações que visem este fim, cujas práticas devem ser motivacionais, especialmente quando envolverem crianças, partindose da premissa que todos podem aprender, mas ao mesmo tempo que todo ser humano é único. A primeira infância, segundo estudos de Adorno, a partir da leitura de Freud, é a fase ideal para que uma criança inicie o processo de emancipação rumo à autonomia. Quanto mais velha a pessoa for, mais difícil será a concretização desse processo. Contudo, vale ressaltar, que o educar à autonomia não pode ser confundido com talento, pois é um erro achá-lo algo inato. $\mathrm{Na}$ verdade, talento deve ser associado ao desafio. A aptidão para algo pode ser desenvolvida pelo ensino e prática. Por meio do esclarecimento deve-

\footnotetext{
${ }^{1}$ Entendemos que a Educação, em sentido lato, perpassa vários domínios e a Biblioteconomia é um deles. Logo, o mesmo espírito da Educação concebido por Adorno pode ser vislumbrado em algumas ações específicas de uma biblioteca.
} 
se superar o falso conceito de talento para que possamos chegar na questão da emancipação. Se assim é, podemos levar as pessoas a aprenderem, por meio da motivação, um modo particular de desenvolvimento da emancipação (ADORNO, 2011).

No processo de autoridade pelo qual a criança passa é necessário a fase do desenvolvimento normal, tal como Adorno (2011) expõe a visão de Freud acerca do assunto. Segundo Freud, nosso aparelho psíquico é formado pelo ID (inconsciente) Ego (consciente) e Superego (aparelho moral). O processo sadio de autoridade faz parte da formação do Ego e Superego, fundamentais na vida em sociedade. Sendo assim, a autoridade é fundamental no processo de formação da criança. Nesta fase, a criança identifica-se com a figura, geralmente, paterna, que lhe expressa autoridade, interiorizando-a, apropriandoa. Contudo, essa etapa deve ser superada, pois se não for, será danosa à construção da personalidade do indivíduo (MARCUSE, 1998). A partir dessa superação se inicia a fase da emancipação. "A emancipação precisa ser acompanhada de uma certa firmeza do eu" (ADORNO, 2011, p. 180).

É importante ressaltar, que a autoridade exercida não deve ser violenta, mas sim esclarecida, ou seja, na medida certa. Não devemos abandonar a criança à própria sorte, mediante uma liberdade extrema, porque se assim for, não será formado um aparelho psíquico consistente, que seja capaz de emancipar o indivíduo. Deixar uma criança totalmente livre, principalmente na primeira infância, é privá-la de ser autônoma numa fase posterior de sua vida. Nesse sentido, expõe Adorno:

Determinadas manifestações de autoridade, que assumem um outro significado, na medida que já não são cegas, não se originam do princípio de violência, mas são conscientes, e, sobretudo, que tenham um momento de transparência inclusive para a própria criança; quando os pais "dão uma palmada" na criança porque ela arranca as asas de uma mosca, trata-se de um momento de autoridade que contribui para a desbarbarização (ADORNO, 2011, p. 167).

Todavia, na acepção dos idealizadores da Escola de Frankfurt, fundamentados na Teoria Crítica, apesar de toda dimensão do eu, trazida pela contribuição de Freud, o conhecimento é relacional, ou seja, se estabelece na 
realidade, pela reflexão do contexto econômico, político, social e cultural no qual estamos inseridos. O conhecimento pode ser considerado um processo individual, mas se constrói no cotidiano, associando teoria e práxis.

Esta afirmação dos filósofos da Escola de Frankfurt nos remete, no âmbito da Ciência da Informação, à Epistemologia Social de Sheran e Egan que, em linhas gerais, retrata os processos informacionais e a construção do conhecimento de modo relacional, como uma construção social. Para tanto, parte do pressuposto de que a informação não pode ser dissociada da sua dimensão coletiva, de modo que o pensamento só pode ser comunicado integrando-se a um modelo social que contemple a coletividade e a interação entre sujeito, conhecimento e prática social (SHERA, 1977).

Assim como a necessidade de informação orienta o indivíduo, assim também orienta as sociedades. É a base do comportamento coletivo, tanto quanto o individual [...]. Mas para ser transmitido dentro de um grupo e absorvido por qualquer grupo, o que é conhecido por cada um dos membros deve ser comunicado e comunicável (SHERA, 1977, p. 9).

Sob este prisma, podemos afirmar que o intelecto humano tem origens biológicas e sociais, não podendo ser visto como uma entidade absoluta, independente, dissociada do contexto histórico-social. Segundo Horkheimer (2013, p. 61) ele "[...] foi declarado ser assim apenas como resultado da divisão social do trabalho, a fim de justificar esta última na base da constituição natural do homem". Posto isto, ações como, dirigir, planejar e organizar são compreendidas como funções do intelecto, em oposição às funções manuais da produção, mas, geralmente, ambas dirigidas pela razão técnica, sem um fim que ultrapasse a dimensão do ganho pessoal.

Ao trazermos a questão ao âmbito da biblioteca, podemos considerar que o papel do bibliotecário não pode se resumir aos procedimentos técnicos de aquisição do acervo, classificar, indexar, desenvolver coleções, entre outros. Muito embora, muitas dessas ações, atualmente, exijam mais reflexão do profissional.

Apesar de Horkheimer, na obra "Eclipse da Razão" (2013), não tratar diretamente da classificação bibliográfica tal como é entendida na literatura 
brasileira de Ciência da Informação, "[...] isto é, a classificação do conhecimento registrado em livros e outros documentos bibliográficos stricto sensu" (MOREIRA; MORAIS, 2019, p. 229), ele expõe que a faculdade do intelecto que envolve classificação está voltada à razão subjetiva, ou seja, é sinônimo de razão técnica. Nas palavras de Horkheimer:

Mas a força que basicamente se torna possível as ações racionais é a faculdade de classificação, inferência e dedução, não importando qual o conteúdo específico dessas ações: ou seja, o funcionamento abstrato do mecanismo de pensamento. Este tipo de razão é chamada de razão subjetiva (HORKHEIMER, 2013, p.13, grifo nosso).

O bibliotecário, como outros profissionais, não pode ser refém da razão instrumental ou subjetiva, tem que ir além dela e encontrar um sentido para suas ações que envolvam o bem comum. É necessário que ele atue também como um educador, um gestor, um mediador da informação, um agente promotor de práticas que resgatem a razão objetiva, auxiliando no processo emancipatório dos indivíduos, principalmente no das crianças. Nesse sentido, Shera (1977), desde a década de 1960, já estabelecia que a tecnologia é extremamente importante, a fim de minimizar o tempo do profissional em suas funções mais técnicas, todavia, nada substitui o talento e a criatividade humana.

Pois o bibliotecário fará mal sua tarefa se não compreender todo o papel do conhecimento na sociedade que ele serve e a parte que as máquinas podem realizar no processo da "ligação do tempo". O bibliotecário é o supremo "ligador do tempo", e sua disciplina é mais interdisciplinar de todas, pois é a ordenação, relação e estruturação do conhecimento e dos conceitos (SHERA, 1977, p. 11).

Portanto, para que o profissional da informação ajude no processo emancipatório, reflexivo e crítico do usuário, é necessário que compreenda que a tecnologia é sempre um meio eficaz e necessário, que auxilia no processo de conhecimento e autonomia, mas nunca um fim em si mesma. $O$ foco deve ser sempre o usuário, suas expectativas, necessidades e demandas, e nunca a tecnologia ou os anseios pessoais do profissional, visando apenas os procedimentos que facilitem seu trabalho. 


\section{A DIMENSÃO SOCIAL DAS BIBLIOTECAS PÚBLICAS E OS MAKERSPACES}

Tratarmos de educação e emancipação nos remete às bibliotecas públicas que são instituições sociais por excelência que, preservam, organizam, processam, medeiam, compartilham e disseminam informação, além de serem equipamentos culturais voltados à construção de conhecimento, cultura e cidadania. Seu conceito, ao longo dos séculos, passou por significativas mudanças e transformações, ressignificando seu papel e concentrando várias funções. Sob esse prisma, além da custódia, guarda e preservação dos registros do conhecimento, as bibliotecas públicas passaram a atuar de maneira ativa, interativa e dinâmica. Os novos paradigmas vigentes na atualidade exigiram e exigem novos serviços, projetos e ações que atendam não só as demandas informacionais, literárias e culturais da população, mas que contribuam com novos processos de inclusão, construção de significados e cidadania no cotidiano social.

Dessa maneira, essas instituições são também espaços de emancipação que se dá através das partilhas e das práticas que conectam e transformam os cidadãos e, consequentemente, a sociedade onde estes estão inseridos. De acordo com o Manifesto da Unesco (1994, p. 1) para as bibliotecas públicas: “[...] o desenvolvimento da sociedade e dos indivíduos são valores humanos fundamentais. Só serão atingidos quando os cidadãos estiverem na posse da informação que Ihes permita exercer os seus direitos democráticos [...]". Assim, mediar e disseminar a informação, proporcionar o acesso aos livros, à leitura, à literatura, as atividades culturais e a memória cultural da humanidade são funções singulares das bibliotecas públicas.

Para isso, os profissionais da informação devem se atualizar constantemente, pois a sociedade atual é complexa, dinâmica e exige novas competências e habilidades para atuarem com excelência neste setor. Desse modo, conhecer as políticas públicas e diretrizes relacionadas às bibliotecas, a complexidade dos recursos informacionais existentes atualmente, bem como as 
metas do Plano Nacional de Cultura e as novas estratégias de ação, é crucial para que essas instituições exerçam com plenitude sua função na sociedade contemporânea. Almeida (1987, p. 36) afirma que:

[...] não se considera mais adequado para a biblioteca $o$ bibliotecário que só sabe biblioteca, ou seja, que tem apenas competência técnica para trabalhar com o seu objeto, a informação. A informação em si não provoca nada de novo. É preciso colocá-la em circulação de tal forma que ela passe a adquirir significado para as pessoas, que ela, de fato interfira na vida das pessoas. Para isso o bibliotecário deve conhecer muito mais do que a forma de seu objeto; deve dominar seu conteúdo.

As bibliotecas devem ampliar e propor novas iniciativas e transcender os limites de seu espaço físico, indo ao encontro dos cidadãos. Assim, os bibliotecários, além do conhecimento técnico da área, devem refletir a respeito dos contextos social, político e econômico, nos quais as bibliotecas estão inseridas, para atuarem com efetividade ante a esse desafio.

Para tanto, é imprescindível uma gestão alicerçada no planejamento e desenvolvimento de projetos, visando ações educativas e culturais, que contribuam para a formação de um leitor autônomo, crítico e reflexivo, propiciando sua emancipação e, consequentemente, uma nova sociedade. Almeida Júnior (1997, p. 22) afirma que: "A biblioteca pública deve ser reflexo e causa das transformações da sociedade [...]". Nessa perspectiva, é necessário estabelecer metas, desenvolver estratégias de ação inovadoras, atuando de maneira interativa, sistematizada e transformadora. Entre as atividades que podem ser desenvolvidas pela biblioteca pública com esse objetivo, pode-se destacar:

a) Contação de histórias: esta atividade pode ser realizada com vários objetivos, entre eles o de inserir o livro e a literatura no cotidiano da vida das crianças e adolescentes, instigando-os a entrar para o mundo da leitura;

b) Encontro com escritor: propiciar o contato com escritores, pois é uma maneira de incentivar à leitura, bem como dinamizar as ações voltadas a aprendizagem que motivem o público em relação aos processos de criação;

c) Lançamento de Livros: oferecer gratuitamente seu espaço aos escritores locais e regionais, para realizarem lançamentos de suas obras e, assim, se aproximarem cada dia mais da sociedade;

d) Exposições: proporcionar o acesso às mais diversas expressões culturais, exposições de arte em geral, visto que representam uma leitura/releitura ou reprodução da história cultural do País ou do mundo e possibilita debates e interações, entre o público e o artista;

e) Palestras educativas: cujo objetivo é propiciar informações diversas e utilitárias 
para a formação e emancipação do cidadão e, também, atuar como "[...] centro local de informação, tornando prontamente acessíveis aos seus utilizadores 0 conhecimento e a informação de todos os gêneros" (UNESCO, 1994);

f) Sarau literário: além de ser um lindo momento de interação, promove a sensibilização, a oralidade e um novo olhar para a poesia, para a prosa, instigando o público a ler;

g) Concursos de leitura e de redação: estimulam a leitura, a escrita e a frequência na biblioteca pública;

h) Oficinas de leitura, de desenho, de grafite, de artesanato: propiciam o acesso a diversidade cultural, pois "[...] além de disponibilizar a informação, a biblioteca pública também deve exercer seu papel cultural. O ambiente deve ser propício para manifestações artísticas de todos os tipos [...]" (JACINTO, 2004, p. 97);

i) Círculo de debates: ação importante que medeia o conteúdo de uma determinada obra, de um filme ou a respeito de um determinado tema da atualidade junto ao público. Estimula a leitura e propicia o acesso a cidadania. De acordo com Moura (1996, p. 88), "[...] o acesso à cidadania plena, conforme os apelos de sua natureza só são obtidos por um processo educativo";

j) Concertos musicais: torna a biblioteca mais viva e propicia o acesso da população aos bens culturais.

k) Hora da informação: traz temas inter-relacionadas às necessidades e demandas locais e regionais sobre distintos assuntos, desde a área da saúde até a área jurídica, proporcionando conhecimento sobre assuntos que afetam diretamente a população local.

As práticas supracitadas são apenas algumas das atividades culturais que podem ser realizadas nas bibliotecas públicas, visando uma atuação proativa e dinâmica, dialogando com a sociedade e interagindo com o leitor, contribuindo com a formação do indivíduo e com a transformação social. A biblioteca pública é lugar de conhecimento, lazer e fruição cultural. Além dos serviços básicos oferecidos, desenvolver projetos culturais e literários, associados à ações inovativas, explorando também as Tecnologias de Informação e Comunicação (TIC) e as redes sociais, uma vez que se constituem em estratégias essenciais para a atuação das bibliotecas públicas no Século XXI.

Nesse cenário fértil para a reflexão acerca do papel das bibliotecas públicas no século XXI, podemos vislumbrar os makerspaces, originários dos Estado Unidos da América (EUA), como tendência no âmbito das bibliotecas, sejam escolares ou públicas. O makerspace, que pode ser compreendido como "espaço do inventor", em linhas gerais, se trata de um local que propicia o uso de TICs e de outras ferramentas, a fim de implementar projetos individuais ou coletivos, cujo ambiente se apresenta como: flexível, colaborador, integrador, de modo que as pessoas se sintam à vontade e com desejo de ali estarem (MARQUINA, 2017). Nesse espaço alternativo, os usuários têm acesso às TICs, 
além de diversas atividades "[...] para além das normalmente permitidas e tradicionalmente disponibilizadas pelas bibliotecas, como por exemplo atividades de leitura, acesso à internet, estudo, aulas, hora do conto, dentre outras" (SANTOS NETO; ZANINELLI, 2017, p.2634).

O movimento maker nas bibliotecas é uma iniciativa promovida pela American Library Association (ALA)2, cujo escopo não é somente oferecer acesso às tecnologias, mas também desenvolver habilidades nos usuários, aumentando suas competências informacionais e digitais, para que os mesmos possam viabilizar suas ideais e seus projetos. Se assim procede, se torna necessário que exista um imbricamento "[...] entre a comunidade - real e potencial - e a tecnologia, que a cultura maker seja incorporada pelos profissionais que trabalham no espaço e que a criatividade das pessoas seja incentivada pelas bibliotecas" (SANTOS NETO; ZANINELLI, 2017, p. 2651).

Apesar de os makerspaces agregarem novas alternativas, deixando 0 espaço das bibliotecas mais atrativos, bonitos, podendo parecer com o de grandes livrarias ou centros culturais, podemos afirmar que muitas atividades realizadas nesses espaços, já estão presentes em muitas bibliotecas públicas de todo o país, mesmo que de modo mais modesto, ante a ausência de políticas públicas eficientes, previsão orçamentária adequada e, principalmente, vontade política para implementá-las. Sendo assim, o conceito, guardadas as devidas proporções, não é algo "novo", mas sem dúvida auxilia o desenvolvimento de competências e habilidades que promovam maior autonomia dos usuários.

A promoção de atividades que realmente desenvolvam conhecimento, reflexão e sensibilidade, não passa apenas por um espaço físico inovador e atrativo, mas é fruto da criatividade dos gestores das bibliotecas. Aliada a ideia de lugar, há o sentimento de pertencimento, do sentir-se bem, do aconchego e da partilha de um espaço coletivo público que pode agregar conhecimento, cultura e lazer (OLIVEIRA, 2017). A biblioteca pública, no que tange a sua função

\footnotetext{
2 Disponível em: /http://www.ala.org/tools/atoz/makerspaces e http://www.ala.org/pla/resources/tools/technology/makerspaces . Acesso em: 17 ago. 2020.
} 
social, precisa refletir acerca das necessidades imediatas e mediatas da comunidade onde está inserida. "Como obrigação social da profissão, deve-se trabalhar para fazer da biblioteca, em quaisquer instâncias, instituição aconchegante e segura" (RIGHETTO; CUNHA; VITORINO, 2019).

Sob esse olhar, que também agrega as reflexões pertinentes aos aspectos da Teoria Crítica, discutidos na seção anterior, argumenta Johnson (2013 apud GASQUE; CASARIN, 2016, p. 47) "[...] as bibliotecas deveriam ser espaços onde as crianças e jovens possam compartilhar informação e não apenas absorvê-la". Esta afirmação de Johnson ratifica o papel da biblioteca como espaço para o desenvolvimento da reflexão crítica, criatividade, sensibilidade e, portanto, de atitudes que agregam ao processo emancipatório, principalmente das crianças. Nesse sentido:

Refletindo sobre a relação entre o equipamento cultural e a cidade, propõe que, nos novos ambientes onde a arte e a cultura circulam, o primeiro deve se tornar um elemento do processo criativo, modificando sua função e estrutura. Museus, centros culturais e bibliotecas são desafiados a repensar a si mesmos, a reconsiderar os laços que estabelecem com seus públicos e com a cidade. Isto implica uma reflexão articulada sobre a ideia de participação e proximidade que se origina de formas de interação criativa [...] (OLIVEIRA, 2017, p. 205).

Posto isto, podemos afirmar que a biblioteca pública tem função sócio educadora e cultural, bem como deve estar atenta aos desafios e demandas da sociedade

\section{VISÃO E AÇÕES DOS COORDENADORES DAS BIBLIOTECAS}

Aplicamos um questionário a dois coordenadores de bibliotecas públicas, contendo três perguntas, ressaltando que ambos são graduados em Biblioteconomia, e um deles é mestre e doutorando em Ciência da informação. As questões foram as seguintes: 1) É possível que a biblioteca possa contribuir efetivamente com o desenvolvimento da autonomia e de experiências formativas, especialmente nas crianças? Justifique sua resposta; 2) A biblioteca pública, onde você trabalha, desenvolve ações que promovam a educação para a emancipação, seja pela reflexão crítica, ou que desenvolva a sensibilidade dos 
Mariana Rodrigues Gomes de Mello, Daniel Martínez- Ávila, Leda Maria Araujo, Marta Lígia Pomim Valentim

Entre técnica e reflexão: um estudo da função social das bibliotecas públicas a partir da Teoria Crítica

usuários? Se afirmativo, quais são? 3) Considerando-se que a construção do conhecimento deve resultar de um processo reflexivo que tem início na busca por informações, você entende que o bibliotecário pode atuar também como agente provocador de mudanças educacionais?

Por meio da análise das categorias definidas a posteriori, foi possível apresentar os seguintes resultados, sintetizados nos Quadros 1, 2 e 3, ante as respostas dos bibliotecários, coordenadores das duas bibliotecas públicas selecionadas (no quadro representados como E1 e E2):

\section{Quadro 1 - Categoria - Desenvolvimento da autonomia em crianças.}

Categoria: Existe promoção da autonomia do usuário no âmbito das bibliotecas públicas

Definição: A biblioteca pública contribui para o desenvolvimento da autonomia e experiência formativas, principalmente das crianças, pois além de disponibilizar o acervo, organiza o espaço e o sinaliza de modo a orientar melhor o leitor acerca de como acessar a informação desejada. Além disso, a forma de atuação das bibliotecas pode ocorrer de maneira diversa, por meio de oficinas palestras, debates, rodas de leituras, desenvolvimento de coleção diversificada, entre outros.

Tema: Exemplos de verbalização

E1: "Acredito que a biblioteca possa contribuir com o desenvolvimento da autonomia e experiências formativas para as crianças, à medida que, além de disponibilizar o acervo, também organiza e sinaliza o espaço de forma a orientar o leitor o mais claramente possível sobre como acessar a informação que ele deseja. Também considero que atividades culturais como oficinas, rodas de leitura ou bate-papo com o escritor, por estimularem a participação, a troca de opiniões, aprendizados, experiências pessoais e leitura de mundo dos participantes, podem contribuir para o desenvolvimento da autonomia e experiências formativas das crianças".

E2: "Creio que seja possível que as bibliotecas atuem no sentido de auxiliar no desenvolvimento da autonomia de todos os indivíduos, especialmente das crianças. Acredito que a forma de atuação das bibliotecas nesse sentido pode se dar de maneiras diversas, lançando mão de, por exemplo, oficinas, palestras, debates, desenvolvimento de uma coleção diversificada e coerente com as demandas e necessidades da comunidade onde a biblioteca se encontra".

Fonte: Elaboração própria com base nos dados coletados (2019).

Quanto a categoria: "desenvolvimento da autonomia em crianças", obtivemos as opiniões dos entrevistados e, por meio da análise e interpretação das informações obtidas, chegamos as seguintes inferências: esta categoria indica que há promoção da autonomia no âmbito das bibliotecas públicas, à medida que a biblioteca pública contribui para o desenvolvimento da autonomia 
e experiências formativas, sobretudo em crianças, pois além de disponibilizar o acervo e realizar ações culturais, organiza o espaço, a fim de orientar melhor o usuário acerca de como acessar a informação desejada.

Estabelecendo um paralelo com o referencial teórico, importante para propiciar o embasamento do estudo, podemos constatar que a questão da organização do espaço da biblioteca é relevante para o processo de emancipação do usuário, pois sinaliza a maneira mais adequada dele obter uma informação. A pergunta não foi voltada especificamente aos makerspaces, tema subsidiário do marco teórico, mas a questão espacial em uma biblioteca aparece, portanto, em uma das respostas como elemento basilar para a construção do princípio da autonomia em bibliotecas.

Quadro 2 - Categoria - Ações que promovem a educação emancipatória.

Categoria: Existem ações na biblioteca pública que promovam uma educação para a emancipação

Definição: As bibliotecas públicas desenvolvem ações, visando uma educação para a emancipação, seja pela reflexão crítica ou mediante projetos que desenvolvam a sensibilidade dos usuários. Para tanto, são promovidas atividades culturais diversas.

Tema: Exemplos de verbalização

E1: "Sim, são promovidas atividades culturais, como dramatização musical com história, a partir da qual foi realizada uma reflexão final sobre o bullying nas escolas; além de oficinas de dobradura, nas quais, após a leitura de um gibi sobre o papel dos imigrantes na formação do Brasil (portugueses, espanhóis, italianos, holandeses, etc.), os participantes fizeram uma reflexão sobre a situação dos atuais imigrantes do Brasil (haitianos, venezuelanos e etc.)".

E2: "De certa forma sim, projetos e ações voltadas a fomentar o contato da comunidade com o livro, a leitura e outras manifestações culturais ocorrem, e os resultados apresentam-se positivos".

Fonte: Elaboração própria com base nos dados coletados (2019).

No que se refere a segunda categoria: "ações que promovem a educação emancipatória", a partir das opiniões coletadas junto aos coordenadores das bibliotecas selecionadas, foi possível sistematizar as informações obtidas e, por meio da análise e interpretação, estabelecemos as seguintes inferências: observamos que há ações nas bibliotecas públicas que promovam uma educação voltada à emancipação, seja por intermédio da reflexão crítica ou por meio de projetos que desenvolvam a sensibilidade dos usuários. Para tanto, são realizadas atividades culturais como a dramatização musical com história, a qual 
Entre técnica e reflexão: um estudo da função social das bibliotecas públicas a partir da Teoria Crítica

possibilitou uma reflexão final sobre o bullying nas escolas, além de oficinas de dobradura, leitura e outras manifestações culturais.

Em relação às reflexões oriundas da Teoria Crítica, associando-as ao conteúdo das opiniões obtidas, observamos que os bibliotecários pesquisados acreditam que a biblioteca pública onde atuam realiza ações que visam fomentar a autonomia, e a partir delas, promove a emancipação dos usuários. Ao analisarmos essas ações, podemos constatar que as bibliotecas públicas pesquisadas promovem o bem comum, saindo da esfera da razão subjetiva (técnica) e adentrando à razão objetiva (emancipatória) com práticas de conteúdo finalístico e social (ADORNO; HORKHEIMER, 1985).

Quadro 3 - Categoria - Bibliotecário enquanto agente de mudança educacional.

Categoria: O bibliotecário pode atuar enquanto agente de mudanças educacionais

Definição: Considerando-se que a construção do conhecimento deve resultar de um processo reflexivo que tem início na busca por informações, o bibliotecário pode atuar como agente promotor de mudanças nas práticas educacionais.

Tema: Exemplos de verbalização

E1: "Considero que o bibliotecário possa atuar tanto na mediação da informação, seja com a sugestão de livros que apresentem pontos de vista diferentes, bem como na mediação de uma pesquisa escolar, na qual pode incentivar a utilização de diversas fontes de informação. O bibliotecário também pode atuar junto à equipe pedagógica, com a programação conjunta de atividades de leitura e pesquisa que estimulem a aprendizagem para vida dos educandos, para que os mesmos aprendam a aprender".

E2: "Pessoalmente entendo que todos os bibliotecários são envolvidos com mudanças educacionais, mas principalmente as bibliotecas escolares e as públicas podem atuar com maior ênfase, como uma ferramenta de apoio do sistema educacional, em conjunto com os demais profissionais da Educação".

Fonte: Elaboração própria com base nos dados coletados (2019).

No que tange a terceira e última categoria: "bibliotecário enquanto agente de mudança educacional", por meio das opiniões coletadas junto aos coordenadores das bibliotecas selecionadas, foi possível estruturar as informações obtidas e, ante a análise e interpretação, conseguimos estabelecer as seguintes inferências: esta categoria evidencia que o bibliotecário pode atuar também como agente educacional, tanto como mediador da informação, seja sugerindo livros que apresentem pontos de vista diversos, seja na mediação de uma pesquisa escolar, na qual pode incentivar a utilização de uma gama de fontes de informação. $O$ bibliotecário também pode realizar um trabalho em 
conjunto com a equipe pedagógica de uma escola, propondo atividades tais como leituras e pesquisas que estimulem a aprendizagem ao longo da vida dos educandos, de modo que "aprendam a aprender".

Analisando esta categoria percebemos que o papel social e educacional do bibliotecário é evidenciado, uma vez que a função socioeducativa e cultural da biblioteca pública deve ser prioritária. Tal fato ratifica que o bibliotecário pode atuar como um educador e mediador da informação, um profissional criativo e humanista que visa práticas que auxiliem no processo emancipatório dos indivíduos, principalmente no das crianças.

\section{CONSIDERAÇÕES FINAIS}

Retomando a questão suscitada na introdução: o bibliotecário está preparado para promover ações que contribuam à formação de seres autônomos, críticos e almeja isso? Apesar da pequena re-presentatividade da amostra, ante a aplicação do questionário em bibliotecas seletas, podemos, por meio da revisão bibliográfica, vislumbrar uma tendência para dimensão emancipatória nas bibliotecas públicas do país, mediante rela-tos na literatura de uma gama de ações dos bibliotecários que corroboram o desenvolvimento da autonomia dos usuários. Logo, o posicionamento dos bi-bliotecários que responderam ao questionário serve para ratificar ações que a literatura já apresenta. $O$ caráter inovador dessa pesquisa incide em nomear essas ações como técnicas ou emancipatórias à luz da Teoria Crítica, na sua primeira geração, destacando-se Adorno e Horkheimer.

Portanto, acreditamos que além da dimensão técnica que a biblioteca pública traz, que é inerente ao seu funcionamento, há outras que requerem uma reflexão maior, à medida que o bibliotecário tem também a função de mediador da informação e educador no sentido lato, orientando o acesso e a busca da informação, e fomentando a vontade de aprender dos usuários. Apesar dos poucos recursos orçamentários e políticas públicas que realmente corroborem para o processo de emancipação dos usuários, verificamos que os bibliotecários têm consciência do papel social da biblioteca pública e mediante a consciência 
de sua responsabilidade social e de muita criatividade conseguem realizar ações que tornam os usuários mais independentes.

O processo emancipatório, como podemos compreender pelo estudo da Teoria Crítica, perpassa pela reflexão, sensibilização e independência. Organizar os espaços das bibliotecas públicas de modo a instigar a vontade de aprender e facilitar o acesso e a busca de informação é um passo importante na promoção da autonomia. Quando o profissional almeja o bem comum, isto é, um fim altruístico, e não apenas os meios que facilitem seu trabalho e otimizem seu tempo, ele sai da razão técnica ou instrumental e adentra a razão objetiva (emancipatória, reflexiva). A partir da noção de alteridade, ao colocar-se no lugar do outro e tê-lo como fim e não como meio, o profissional ultrapassa a esfera da técnica e da materialidade, passando a ser ético. Por mais reflexiva que possa parecer uma função, se não houver um fim maior do que o olhar voltado a si mesmo, esta estará no campo da técnica.

\section{REFERÊNCIAS}

ADORNO, T. W; HORKHEIMER, M. Dialética do esclarecimento. Rio de Janeiro: Zahar, 1985.

ADORNO, T. W. Educação e emancipação. 2.ed. São Paulo: Paz e Terra, 2011.

ALMEIDA, M. C. B. de. A ação cultural do bibliotecário: grandeza de um papel e limitações da prática. Revista Brasileira de Biblioteconomia e

Documentação, São Paulo, v.20, n.1/4, p.31-38, jan./dez. 1987. Disponível em: http://www.brapci.inf.br/_repositorio/2011/08/pdf_bf26644cf9_0018444.pdf. Acesso em: 14 ago. 2019.

ALMEIDA JUNIOR, O. F. de. Bibliotecas públicas e bibliotecas alternativas. Londrina: EDUEL, 1997.

ARISTÓTELES. Tópicos: dos argumentos sofísticos. Metafísica: livro I e livro II. Ética a Nicômaco. Poética. São Paulo: Abril Cultural, 1973. 533p. (Os Pensadores, 4).

SANTOS NETO, J. A. dos; ZANINELLI, T. B. Biblioteca escolar como makerspace: um estudo de caso na Biblioteca Abraham Lincoln. Revista 
Brasileira de Biblioteconomia e Documentação, São Paulo, v.13, n. esp. CBBD, p. 2633-2656, 2017. Disponível em:

http://www.brapci.inf.br/index.php/res/download/42026. Acesso em: 14 ago. 2019.

BARDIN, L. Análise de conteúdo. São Paulo: Edições 70, 2009.

CONTRIN, G.; FERNANDES, M. Fundamentos de Filosofia. São Paulo: Saraiva, 2013.

DEMO, P. Ambivalência da Sociedade da Informação. Ciência da Informação, Brasília, v.29, n.2, p.37-42, maio/ago. 2000. Disponível em:

http://revista.ibict.br/ciinf/article/view/885/920 Acesso em: 14 ago. 2019.

FREIRE, P. Pedagogia da autonomia: saberes necessários à prática educativa. São Paulo: Paz e Terra, 2011.

GASQUE, K. C. G. D.; CASARIN, H. de C. S. Bibliotecas escolares: tendências globais. Em Questão, Porto Alegre, v.22, n.3, p.36-55, set./dez. 2016.

Disponível em: https://seer.ufrgs.br/EmQuestao/article/view/60697. Acesso em: 14 mar. 2019.

HORKHEIMER, M. Eclipse da razão. São Paulo: Centauro, 2013.

JACINTO, S. de O. A biblioteca pública e os deficientes físicos. Revista Brasileira de Biblioteconomia e Documentação, São Paulo, v.4, n.2, p.89104, jul./dez. 2004. Disponível em:

http://rbbd.febab.org.br/rbbd/article/view/92/146. Acesso em: 28 jan. 2019.

JOHNSON, Doug. Power up!/The new school library. Leveraging Teacher Leadership, v.71, n.2, p.84-85, Oct. 2013.

KANT, I. Textos seletos. 2.ed. São Paulo: Vozes, 1985.

MARCUSE, H. Cultura e sociedade. Rio de Janeiro: Paz e Terra, 1998. v.2.

MANIFESTO DA UNESCO, 1994. Disponível

em:https://www.ifla.org/files/assets/public-libraries/publications/PL-manifesto/plmanifesto-pt.pdf. Acesso em: 20 mar. 2019.

MARQUINA, J. Makerspaces en bibliotecas: el fenómeno Bibliomakers. 2017. Disponível em: http://www. Julianmarquina.es/makerspaces-en-bibliotecas-elfenomeno-bibliomakers/. Acesso em: 20 mar. 2019.

MOREIRA, W.; MORAES, I. S. O assunto "classificação" na literatura brasileira de Ciência da Informação: uma análise nos anais do ENANCIB (2003-2014). Informação \& Informação, Londrina (PR), v.24, n.1, p.226-246, 2019. 
Disponível em:

http://www.uel.br/revistas/uel/index.php/informacao/issue/view/1527. Acesso em: 19 mar. 2019.

MOURA, L. D. de (Coord.). Construindo a cidadania. São Paulo: Makron Books, 1996. 104p.

OLIVEIRA, L. M. B. On arches and stones, places and experiments: Public libraries and democratic society. Transinformação, Campinas (SP), v.29, n.2, p.203-210, maio/ago. 2017. Disponível em:

http://www.scielo.br/scielo.php?pid=S0103-

7862017000200203\&script=sci_abstract\&tIng=pt. Acesso em: 15 mar. 2019.

RIGHETTO, G. G; CUNHA, M. F. V.; VITORINO, E. V. O papel social do bibliotecário voltado às pessoas trans: aproximações teóricas. Em Questão, Porto Alegre (RS), v.25, n.1, p.212-238, jan./abr. 2019. Disponível em: https://seer.ufrgs.br/EmQuestao/article/view/80877/50330 Acesso em: 24 abr. 2019.

SHERA, J. H. Epistemologia Social e Biblioteconomia. Ciência da Informação, Brasília (DF), v.6, n.1, p.9-12, 1977. Disponível em: http://revista.ibict.br/ciinf/article/view/92/92. Acesso em: 14 ago. 2019.

SILVA, C. R.; GOBBI, B. C.; Simão, A. A. O uso da análise de conteúdo como uma ferramenta para a pesquisa qualitativa: descrição e aplicação do método. Organizações Rurais Agroindustriais, v.7, n.1, p.70-81, 2005. Disponível em: http://www.redalyc.org/pdf/878/87817147006.pdf. Acesso em: 14 ago. 2019.

SILVA, E. da; VALENTIM, M. L. P. Avaliação da aplicação do método análise do conteúdo em pesquisas sobre processos de gestão da informação e do conhecimento como subsídios para a geração de inovação. Informação \& Informação, Londrina (PR), v.24, n.1, p.326-355, jan./abr. 2019. Disponível em: http://www.uel.br/revistas/uel/index.php/informacao/article/view/31957/pdf. Acesso em: 14 ago. 2019.

TOTTERDELL, B. Public library purpose: a reader. London: Clive Bingley, 1978

\section{BETWEEN TECHNIQUE AND REFLECTION: A STUDY OF THE ROLE OF PUBLIC LIBRARIES BASED ON CRITICAL THEORY}

\section{ABSTRACT}

Introduction: Public libraries are spaces of emancipation through the exchanges, sharing, and practices that connect and transform citizens and consequently the society 
in which they live. Thus, the research question is: are librarians prepared and to promote actions that contribute to the education of autonomous and critical beings? Do they aim at that? Aim: To establish the interrelationship between the role of the public library, the subjective (technical) reason, and the objective (emancipatory) reason using Critical Theory, and especially the philosophers Adorno and Horkheimer. After discussing the fundamental elements of Critical Theory, the role of the librarian in the emancipatory process of users, highlighting the social dimension of public libraries as makerspaces, we present the results of a questionnaire answered by two public library coordinators. Methodology: We applied a "Content Analysis" and more specifically the technique "Categorical Analysis", whose categories were established a posteriori. Results: We found that in addition to the technical dimension that the public library presents, inherent to its operation, there are other aspects that require greater reflection, since the librarian also has the function of information mediator and educator in a broad sense, guiding the access to information, search, and the willingness of users to learn. Conclusion: This emancipatory process, based on the contribution of Critical Theory, permeates the reflections, awareness, and independence. Organizing the spaces of public libraries in order to foster the desire to learn, facilitating the access and search for information, is an important step in the promotion of autonomy.

Descriptors: Social Function in Public Library. Public Library. Critical theory. Maker space.

\title{
ENTRE TÉCNICA Y REFLEXIÓN: UN ESTUDIO DE LA FUNCIÓN DE LAS BIBLIOTECAS PÚBLICAS A PARTIR DE LA TEORÍA CRÍTICA
}

\begin{abstract}
RESUMEN
Introduction: Las bibliotecas públicas se convierten en espacios de emancipación a través de los intercambios y prácticas que conectan y transforman los ciudadanos y, en consecuencia, a la sociedad en la que viven. Por lo tanto, la pregunta es: ¿está el bibliotecario preparado para promover acciones que contribuyan a la formación de seres autónomos y críticos y está eso entre sus objetivos? Objetivo: Establecer la interrelación entre el papel de la biblioteca pública, la razón subjetiva (técnica) y la razón objetiva (emancipadora) a través de la teoría crítica y especialmente los filósofos Adorno y Horkheimer. Se discuten los elementos fundamentales de la teoría crítica, el papel del bibliotecario en el proceso emancipatorio de los usuarios, destacando la dimensión social de las bibliotecas públicas como makerspaces, y presenta los resultados obtenidos de la aplicación de un cuestionario a dos coordinadores de bibliotecas públicas. Metodología: Se utilizó el método de "Análisis de contenido", y más específicamente la técnica "Análisis categórico", cuyas categorías se establecieron a posteriori. Resultados: Se evidenció que, además de la dimensión técnica que aporta la biblioteca pública inherente a su funcionamiento, hay otras dimensiones que requieren una mayor reflexión, ya que el bibliotecario posee también una función de mediador y educador de información en sentido amplio, guiando el acceso, búsqueda de información y fomento de la disposición de los usuarios a aprender. Conclusión: El proceso emancipatorio, basado en la contribución de la teoría crítica, impregna la reflexión, la sensibilización y la independencia. Organizar los espacios de las bibliotecas públicas para instigar el deseo de aprender, facilitar el acceso y la búsqueda de
\end{abstract}


Mariana Rodrigues Gomes de Mello, Daniel Martínez- Ávila, Leda Maria Araujo, Marta Lígia Pomim Valentim

Entre técnica e reflexão: um estudo da função social das bibliotecas públicas a partir da Teoria Crítica

información es un paso importante para promover la autonomía.

Descriptores: Función social de las Bibliotecas Públicas. Biblioteca Pública. Teoría crítica. Makerspace.

Recebido em: 29.11.2019

Acesso em: 02.08.2020 